\title{
Study and Development of Positive Testing System for Screw Drill
}

\author{
SUN Xingwei ${ }^{\mathrm{a}}$, LIU Lei ${ }^{\mathrm{b}}$, FENG Xin ${ }^{\mathrm{c}}$, WANG Ke ${ }^{\mathrm{d}}$ \\ School of mechanical engineering, Shenyang University of Technology, Shenyang, 110870, China \\ asunxingw@126.com, ${ }^{b}$ liu060102037@163.com, ${ }^{\mathrm{c}}$ fengx09@126.com, ${ }^{\mathrm{d}}$ wk2222@sina.com
}

Keywords: screw drill; positive test; performance parameters; data acquisition and processing.

\begin{abstract}
Based on research and analysis of the screw drill working principle, screw drill positive testing system is developed according to screw drill working conditions. This system can obtain the performance parameters of screw drill through testing parameters, such as screw drill power fluid, the pressure of both ends, the output speed and torque, based on the collected data processing. It's illustrated to be practical and feasible in the presence of the example analysis.
\end{abstract}

\section{Introduction}

Screw drilling tool in oil drilling and mining has been widely applied, belong to the rapid development of the global mechanization and automobile industry, the rapid rise of oil and the surrounding areas. The reliability of screw drills' quality gets more and more oil producers' attention. The performance parameters of screw drill and screw motor stator rubber quality are key factors that affect the overall performance of screw drill and drilling speed[1-2]. Therefore, it is necessary to design and use the testing system for screw drill production and use. This article provides theoretical reference of screw drill design and manufacturing for the future, based on the research and analysis the working process of screw drill and test principle of the screw drilling tools detection system. Screw drilling positive testing system detects and collects data by simulating the underground working condition of screw drill, so it's better to declare the working performance of screw drilling tools. This can provide a reliable basis for the use of product, the development of new products and the improvement of product quality[3-5].

\section{Screw drill principle of work}

Screw drill is a new underground power tools widely used in oil drilling and mining. It regards fluid as dynamic through the volumetric motor to provide speed and torque for drill.

The composition of the screw drill as shown in figure 1 shows, The working principle of the screw drill is that mud pump offers flows through the transmission universal shaft drill motor bypass valve by-pass valve into the motor, and the motor import and export has a certain pressure difference to promote rotor rotation stator axis, the speed and torque through the cardan shaft and drive shaft will be passed to the drill in order to achieve the drilling operations.

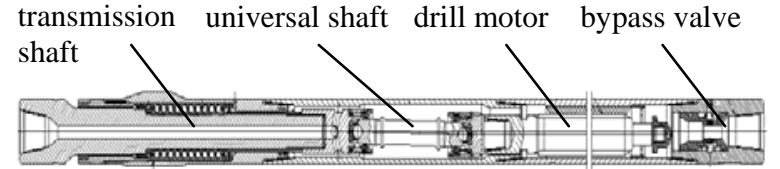

Fig.1 structure of screw drill

From the working principle of the screw drill we can see that the screw drill motors belongs to the drill volumetric liquid driver. On the properties of the test will to provide certain motor pressure and flow of liquid for its normal operation, and on the output end of the screw drill exerts a torque load to simulate drilling getting reverse torque and friction torque in underground work. Therefore, we can provide a given liquid flow value in one end of the screw drill, in this a given flow value, can test out drilling tools in different conditions performance parameters base on the drilling tool output exert different reverse torque load to make the screw drill in different braking torque steady work.

\section{Screw drill the main property parameter}

In the screw drill actual measurement, because drill motors (stator and rotor) and drive shaft parts have the friction between leading to energy consumption of transfer power. The screw drill input 
power $P_{1}(\mathrm{KW})$ can expressed by experience formula as:

$$
P_{1}=Q \bullet \Delta p
$$

The output power of drilling tools $P_{2}(\mathrm{KW})$ :

$$
P_{2}=1.04691 \times 10^{-4} M \bullet n
$$

We can measure drilling efficiency $\eta$ :

$$
\eta=\frac{P_{2}}{P_{1}}=\frac{1.04691 \times 10^{-4} M \bullet n}{Q \bullet \Delta p} \times 100 \%
$$

Notes: $Q$ - Liquid flow $(\mathrm{L} / \mathrm{s}) ; \Delta p$-Drill liquid pressure drop(MPa); $M$-Output torque $(\mathrm{N} \cdot \mathrm{m})$; $n$ - Output speed(r/min).

Because the liquid under pressure, a part of the liquid leakage value $Q$ ' blabs between the rotor and the bushing caused by the rubber bushing radial deformation of the drilling motor stator, while the actual effective flow of the drive rotor:

$$
Q_{a}=Q-Q^{\prime}
$$

Because $Q$ can't be measured directly, therefore the indirect method will to be expressed. Driving motor rotor rotating effective flow can be expressed as:

$$
Q_{a}=n \bullet q / 60
$$

Notes: $q$-Every turn of the rotor theory flow.

In drilling tools idling without considering the friction and torque loss situation, brake torque to zero and screw drill pressure drop small, now we think motor internal leakage smaller or no leakage occurs, input flow are all effective flow this can be expressed as:

$$
q=60 Q_{0} / n_{0}
$$

Notes: $Q_{0}$-Idling drill fluid flow(L/s); $n$-Idling speed of the drill string(r/min).

The drill volume efficiency $\eta_{v}$ can be expressed as:

$$
\eta_{v}=Q_{a} / Q=\frac{Q_{0} \bullet n}{n_{0} \bullet Q} \times 100 \%
$$

Screw drill mechanical efficiency $\eta_{m}$ can be obtained by experience formula:

$$
\eta_{m}=\eta / \eta_{v}=\frac{1.04691 M \bullet n_{0}}{Q_{0} \bullet \Delta p} \times 100 \%
$$

Screw drill theory output torque $M_{c}(\mathrm{~N} \cdot \mathrm{m})$, The empirical formula (9) concluded that:

$$
M_{c}=\frac{\left(p_{c a}-p_{c o}\right) \bullet q_{c} \bullet \eta_{m}}{2}
$$

Notes: $p_{c a}$-Drill motors entrance measured pressure $(\mathrm{Pa}) ; p_{c o}$-The drill no-load drive pressure(Pa); $q_{c}$-Screw motor displacement $\left(\mathrm{m}^{3} / \mathrm{r}\right)$.

\section{The structure of the positive test system}

Design and manufacture a screw drill performance test system, combining the working principle of the screw drill. This system is mainly composed of liquid power cycle module, load brake modules, the data text module and clamping support module four parts. Its structure as shown in figure 2 shows:

Liquid power cycle module. Liquid circulation power module consists of an oil injection pump, all kinds of valve switch, water transmission assembly, high pressure water pipes, water tanks and other components. Injection pump is composed of a multifunctional five cylinder plunger pump; it can satisfy the dynamic fluid flow rate for $55 \mathrm{~L} / \mathrm{s}$, entrance pressure for $10 \mathrm{MPa}$ design. Because test 
need entrance pressure is changed, so we can get through the acquisition parameters for processing to meet the testing requirements of working conditions for controlling the pump input speed, in order to regulate liquid displacement. Water transmission assembly is an important part of the liquid circulation module; its role transfers the physical parameters of drill the output torque, rotational speed to the torque-speed tester, and the liquid in the inner hole of drilling tool

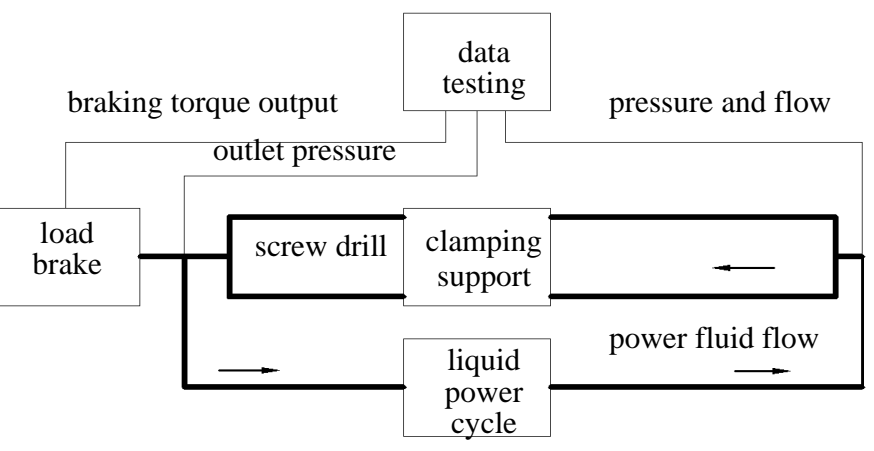

Fig.2 schematic diagram of testing system drive shaft back to the water tank to form a circulation loop.

Load brake module. Load brake system is composed of a $10 \mathrm{kN} \cdot \mathrm{m}$ mechanical brake assembly, the composition of the mechanical braking mechanism is a mechanical disc brake with multiple sets of brake tongs. Each brake caliper is provided braking pressure by the hydraulic system, forms different reverse resistance for simulating the drill different working resistance through the supply pressure regulating to control the positive pressure of brake caliper and the brake disc. This test system adopts hydraulic to control mechanical braking institutions, because controlled by hydraulic mechanical brake assembly can make the braking pressure loading stability, not appear suddenly load too large or small phenomenon in braking process, and the economic benefits.

Data test module. Data testing module is parameters acquisition under various operating for screw drill, and parameters acquisition is the key to reflect the measured screw drill performance, so the precision of the acquisition data has also decided the measured drilling quality, therefore data acquisition has also become one of the key parts of the testing system.

As shown in Fig.3 shows, the testing system collects parameters of import and export pressure, flow, output torque, speed and temperature. These parameters through the data processing will get drilling efficiency and other parameters what we think. Therefore, data acquisition is a complex process.

As shown in Fig.4, the parameters collected by the sensor of torque, speed, fluid pressure, temperature, flow through a circuit transformation put into Micro Control Unit (MCU), then obtained the numerical parameters by the MCU function transform. The operators are according to various different working conditions needed to control water injection pump input speed, thereby to regulate entrance pressure and liquid flow to adapt to different conditions to complete the data collection and test system control.

The clamping support system. The clamping support system is composed by bearing support box, drilling fixed institutions, drill sliding institutions, hydraulic system and the base of test stand. The role of

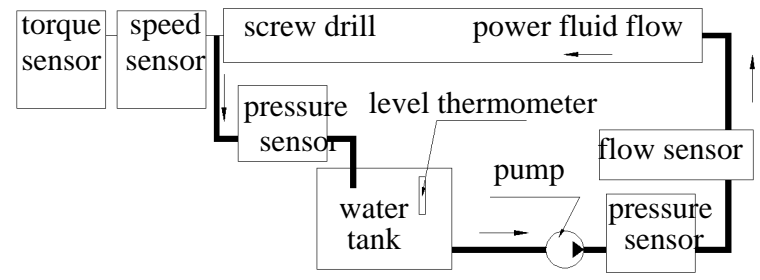

Fig.3 data collection schemes

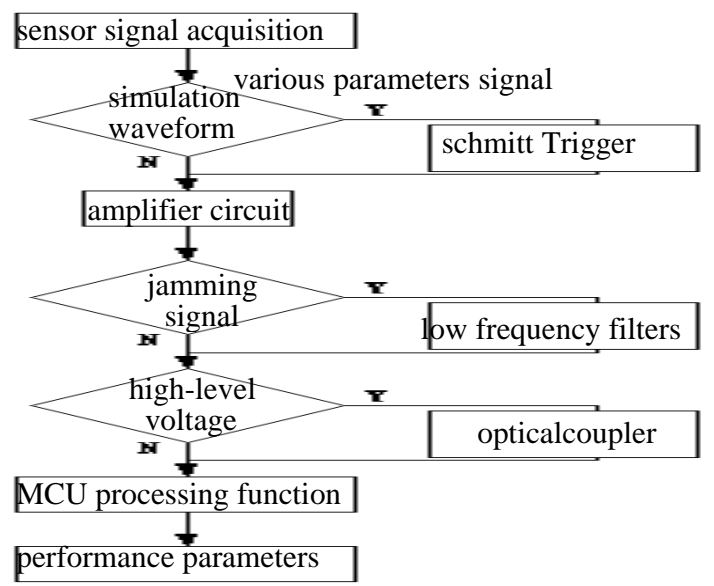

Fig.4 data acquisition and processing flow chart the bearing support box is to bear most of the axial thrust generated by the rotor driven by high pressure liquid, to avoid making the test units damaged due to the axial force too large. Drilling equipment fixed institutions makes the screw drill fixed tightly on the test, to ensure that test process screw drill stator housing can't turn along with the rotation of the rotor. Screw drilling tools push-pull mechanism is the hydraulic mechanical structure that are respectively composed of radial and axial two double-acting hydraulic cylinder .Its role is 
fixed, assembly and dismounted for screw drilling tools used for gripping, push and pull movement. Automatic axial push travel can be up to $900 \mathrm{~mm}$. Because the test time is short, Installed speed is one of the main factors affecting test efficiency, so the system uses quick change joint institutions, through this the disassembly and assembly speeds are greatly improved, and further improve the efficiency of the test system.

\section{The example analysis}

We make a type of screw drilling tool that diameter is $172 \mathrm{~mm}$ for testing, recording the system measured drilling data as shown in table 1:

Table.1 measured screw drill parameters acquisition record

\begin{tabular}{|c|c|c|c|c|c|c|c|c|c|}
\hline \multirow{3}{*}{$\begin{array}{c}\text { Sequence } \\
\text { number }\end{array}$} & \multicolumn{3}{|c|}{ Pressure $\mathrm{MPa}$} & \multirow{2}{*}{$\begin{array}{l}\text { Speed } \\
\mathrm{r} / \mathrm{min}\end{array}$} & \multirow{2}{*}{$\begin{array}{c}\text { Torque } \\
\mathrm{N} \cdot \mathrm{m}\end{array}$} & \multirow{2}{*}{$\begin{array}{c}\text { Flow } \\
\mathrm{L} / \mathrm{s}\end{array}$} & \multicolumn{2}{|c|}{ Power KW } & \multirow{2}{*}{$\begin{array}{c}\text { Efficiency } \\
\%\end{array}$} \\
\hline & Entrance & Export & Pressure drop & & & & Input & Output & \\
\hline & $P_{1}$ & $P_{2}$ & $\Delta P$ & $n$ & $M$ & $Q$ & $P_{1}$ & $P_{2}$ & $\eta$ \\
\hline 1 & 7.3 & 2.4 & 4.9 & 91 & 6477 & 27 & 132.3 & 61.71 & 46.6 \\
\hline 2 & 7.5 & 2.5 & 5.0 & 93 & 6500 & 29 & 145 & 63.29 & 43.65 \\
\hline 3 & 7.2 & 2.1 & 5.1 & 89 & 6737 & 25 & 127.5 & 62.77 & 49.23 \\
\hline
\end{tabular}

The theory design requirements of the main parameters for the measured screw: Drilling pressure: $4.3 \sim$ 5.3MPa;Flow range: $20 \sim 35 \mathrm{~L} / \mathrm{s}$;Torque: $7000 \mathrm{~N}$ m; Speed: $80 \sim 150 \mathrm{r} / \mathrm{min}$;

The main parameters of screw drill can be seen from table 1 in the tested, and efficiency is achieved more than the index of $35 \%$, so this screw drill is qualified. But because of the gap between theory and practice, the obtained data will have a smaller error, the main reason is the motor between stator and rotor combination not ideal. The existence of individual point of contact is excessive extrusion or the gap, so that the actual collection of data has deviation with the theoretical, and data acquisition system in error is one of the reasons lead to biased data.

\section{Conclusions}

The positive detection system can approximate simulation underground work conditions of screw drill, it can directly get the performance parameters of screw drill tool, and can accurately display the performance of screw drilling tool. The test system is according to circular economy principle, and not reduces the precision and efficiency of testing. This system uses the electronic integrated data acquisition system and through the LED display, so that the acquisition data are intuitively and accurately. The use of positive detection system can provide more accurate parameter for screw drilling tools, to improve the screw drill used for drilling tool reliability and provide a reliable basis for the service life of the screw drill.

\section{References}

[1] Zhang Qiang, Li Mingqiang. Development and application of test bed for large torque screw drill[J].China petroleum machinery.2007(7),p.31-34.

[2] Zhu Xiaohua, Tong Hua. Screw drilling tool drive shaft mechanical characteristics evaluation[J]. Qetroleum drilling techniques.2007(1),p.35.

[3] Wang Chunyang, Huang Jiqing.Screw drill the machine performance tests[J].Drilling and production technology.2010(1),P.73-75.

[4] SY/T 5383-2010. Screw drill ( the people's Republic of China petroleum industry standard )[S].

[5] Feng Xiaodi.Installation of rotating speed and torgue sensor for pump/motor test stand[J]. Fluid power transmission and control.2009(6),p.28-30.

[6] Li Nianqiang, Wei Changzhi .Data acquisition technology and system design[M].Beijing: China Machine Press.2009. 